\title{
Study of Cold Tolerance in Blueberry Using EST Libraries, cDNA Microarrays, and Subtractive Hybridization
}

\author{
Lisa J. Rowland, Anik L. Dhanaraj, and Dhananjay Naik \\ U.S. Department of Agriculture, Agricultural Research Service, Genetic Improvement of Fruits and Vegetables \\ Laboratory, Building 010A, BARC-West, 10300 Baltimore Avenue, Beltsville, MD 20705 \\ Nadim Alkharouf \\ Towson University, Department of Computer and Information Sciences, Towson, MD 21252

\begin{abstract}
Ben Matthews
U.S. Department of Agriculture, Agricultural Research Service, Soybean Genomics and Improvement Laboratory, Building 006, BARC-West, Beltsville, MD 20705
\end{abstract} \\ Rajeev Arora \\ Iowa State University, Department of Horticulture, Ames, IA 50011
}

\begin{abstract}
Additional index words. cold hardiness, expressed sequence tags, freezing tolerance, genomics, subtracted library, transcript profiles, Vaccinium
\end{abstract}

\begin{abstract}
To gain a better understanding of changes in gene expression associated with cold acclimation in the woody perennial blueberry (Vaccinium corymbosum $\mathbf{L}$.) and ultimately use this information to develop more freeze-tolerant cultivars, a genomics approach based on the analysis of expressed sequence tags (ESTs) and microarrays was undertaken. Initially, two standard cDNA libraries, constructed using RNA from cold-acclimated (CA) and nonacclimated (NA) floral buds of the blueberry cultivar Bluecrop, were used for the generation of $\approx \mathbf{2 4 0 0}$ ESTs, half from each library. Putative functions were assigned to cDNAs based on homology to other genes/ESTs from GenBank. From contig analyses, 796 and 865 unique transcripts were identified from the CA and NA libraries, respectively. The most highly abundant cDNAs, that were picked many more times from one library than from the other, were identified as representing potentially differentially expressed transcripts. A cDNA microarray was constructed and used to study gene expression under coldacclimating conditions in the field and cold room. Results indicated that the abundance of transcripts of numerous blueberry genes change during cold acclimation, including genes not found previously to be cold-responsive in Arabidopsis, and, interestingly, more transcripts were found to be upregulated under cold room conditions than under field conditions. Finally, forward and reverse subtracted cDNA libraries were prepared from 'Bluecrop' RNA to enrich for transcripts that are expressed at higher levels in floral buds at $400 \mathrm{~h}$ and at $0 \mathrm{~h}$ of low-temperature exposure, respectively. Many genes encoding putative transcription factors and other proteins related to signal transduction were identified from both libraries.
\end{abstract}

Low temperature combined with lack of cold hardiness are among the major causes of plant yield reduction and losses in commerce and the most limiting factor to natural plant distribution (Parker, 1963). Winter injury is one of the most important factors limiting growth of woody perennials in North America (Quamme, 1985). Periodic winter freezes result in serious losses in fruit, nut, and ornamental crops. Consequently, a major emphasis of many breeding programs on woody plants is the development of more cold-hardy cultivars.

To survive the winter, woody perennials of the temperate zone increase their freezing tolerance seasonally by a process known as cold acclimation. Cold acclimation in woody perennials is generally considered a two-step process, first triggered by shortening daylength and then declining temperatures, subsequently into the subfreezing range (Powell, 1987; Sakai and Larcher, 1987; Weiser, 1970). Herbaceous plants, on the other hand, acclimate to maximum cold-hardiness levels by exposure to low, nonfreezing temperatures, and their cold acclimation capacity is generally less than that of woody species (Kacperska-Palacz, 1978). Thus, cold accli-

Received for publication 13 Dec. 2007. Accepted for publication 15 Jan. 2008. mation is considered more complex in woody perennials; woody plants that would be killed by temperatures slightly below $0{ }^{\circ} \mathrm{C}$ during summer may survive temperatures as low as $-196{ }^{\circ} \mathrm{C}$ during winter (Sutinen et al., 1992).

Genetic evidence from both herbaceous and woody plants indicates that cold hardiness is controlled by several genes; thus, it is a quantitative trait (Arora et al., 2000; Byrne et al., 1997; Howe et al., 2000; Jermstad et al., 2001). Considerable molecular and genomic evidence indicates that cold acclimation is a complex phenomenon involving changes in expression of many genes resulting in the alteration of metabolism and composition of cell walls, lipids, proteins, and carbohydrates (Fowler and Thomashow, 2002; Guy, 1990, 1999; Seki et al., 2001; Shinozaki and Yamaguchi-Shinozaki, 1996, 2000; Thomashow, 1999, 2001). Within the last few years, microarrays have been used in Arabidopsis to study changes in gene expression on a large scale during cold stress. Fowler and Thomashow (2002) used commercially available microarrays to examine transcript levels of $\approx 8000$ genes in coldstressed Arabidopsis plants; 306 of these genes were cold-responsive, 218 being upregulated and 88 being downregulated. More than one-fourth of the cold-responsive genes did not appear to be regulated by C-repeat binding factor or $\mathrm{CBF}$ proteins (transcription factors responsible for the upregulation of many genes in response to cold and drought stress), indicating that multiple regulatory pathways are activated during cold acclimation. Maruyama et al. (2004) identified new members of the CBF regulon using microarrays and transgenic plants overexpressing CBFs. A recent article by Hannah et al. (2005) summarizes the microarray data on cold stress in Arabidopsis.

Over the past several years, we have studied the biology of cold tolerance in blueberry with an ultimate goal of applying the information to develop more cold-hardy cultivars. For blueberry, lack of winter freezing tolerance and susceptibility to spring frosts have been identified as the most important genetic limitations of current cultivars (Moore, 1993). Working with a woody perennial, however, the focus of our studies has been different from those in Arabidopsis. For example, our studies have focused on natural, seasonal cold acclimation. We have also focused on flower bud tissue, rather than leaf tissue, because damage to flower buds directly results in reduction in fruit yield. In addition, we have examined changes in gene expression over a longer period of time, throughout the duration of winter. Blueberry reaches maximum freezing tolerance midwinter and some genotypes can acclimate to $\approx-25$ to $-30{ }^{\circ} \mathrm{C}$. See Table 1 for a list of 
cultivars and their levels of flower bud cold hardiness during midwinter. In contrast, Arabidopsis reaches maximum cold tolerance relatively quickly but only cold acclimates $\approx 5$ to $7{ }^{\circ} \mathrm{C}$ allowing for brief exposures to freezing temperatures. Furthermore, we have tried to interpret our findings keeping in mind that overwintering flower buds exhibit both enhanced freezing tolerance and dormancy transitions.

\section{IDENTIFICATION OF COLD-RESPONSIVE DEHYDRINS IN BLUEBERRY}

We initially began our work to identify cold acclimation genes in blueberry by identifying and isolating genes, on a gene by gene basis, that respond to low temperature exposure, reasoning that such genes would be good candidates for involvement in coldhardiness development. We first examined changes in protein levels associated with low-temperature exposure in floral buds of field plants of two blueberry cultivars with different levels of cold hardiness. The cultivars used were relatively cold-tolerant $V$. corymbosum 'Bluecrop' (the industry standard) and more cold-sensitive $V$. ashei Reade 'Tifblue'. From protein profiles, the levels of three proteins of 65,60 , and $14 \mathrm{kDa}$ were observed to increase with low-temperature exposure in floral buds of both cultivars during the winter such that they become the predominant proteins (Muthalif and Rowland, 1994).

Further characterization of the coldresponsive proteins revealed them to be members of a family of proteins known as dehydrins (Muthalif and Rowland, 1994). Dehydrins are a group of heat-stable, glycine-rich plant proteins that are induced by environmental stimuli that have a dehydrative component, including drought, low temperature, salinity, and seed maturation (Close, 1996). Indicative of dehydrins is the presence of a highly conserved lysine-rich amino acid sequence (consensus sequence EKKGIMDKIKEKLPG) referred to as the K segment, which is often repeated several times (Close, 1996). The categorization of the cold-responsive proteins in blueberry as dehydrins was based on several factors, including their reaction to antiserum raised against the dehydrin-specific consensus peptide or $\mathrm{K}$ segment from barley, their heat stability, and the similarity in amino acid composition of selected sequenced peptides from the cold-responsive proteins to dehydrins (Muthalif and Rowland, 1994).

We also found good quantitative correlation between dehydrin accumulation and cold hardiness in blueberry. For example, within a genotype such as 'Bluecrop', we showed that the 65,60 , and $14 \mathrm{kDa}$ dehydrins accumulate during seasonal development of cold hardiness, reaching maximum levels when cold tolerance levels are at a maximum and decreasing during deacclimation and the resumption of growth (Muthalif and Rowland, 1994). Also, we found good correlation between levels of dehydrins and cold-hardiness levels across all blueberry genotypes examined with levels being higher in the more cold-tolerant genotypes and lower in the more cold-sensitive ones (Arora et al., 1997; Muthalif and Rowland, 1994). A fulllength 2.0-kb cDNA clone encoding the 60 $\mathrm{kDa}$ dehydrin was isolated from a cDNA library constructed from floral bud RNA from cold-acclimated 'Bluecrop' plants (Levi et al., 1999). Using a genomic approach (described in the next section), a full-length $0.5-\mathrm{kb}$ cDNA clone encoding the $14 \mathrm{kDa}$ dehydrin was isolated from 'Bluecrop' as well (Dhanaraj et al., 2005).

\section{GENERATION OF ESTS FROM FLOWER BUD TISSUE IN BLUEBERRY}

Because of the complexity and multigenic nature of cold acclimation, and the wide array of genes that have been identified in Arabidopsis as responsive to cold stress, several other genes are likely to play key roles in cold acclimation in blueberry in addition to the previously described dehydrins. Also, work done on herbaceous plants, to overexpress a single cold-responsive gene at a time such as some of the COR genes, has failed to result in enhanced freezing tolerance at the whole plant level (Kaye et al., 1998). However, overexpression of CBF transcription factors has been shown to enhance freezing tolerance in Arabidopsis (Guilmour et al., 2000; JagloOttosen et al., 1998; Kasuga et al., 1999). In recent years, genes encoding CBFs have been isolated from a large number of plants, including sour cherry (Prunus cerasus L.) and strawberry (Fragaria $\times$ ananassa Duchesne) (Owens et al., 2002). Therefore, a genomics approach based on the analysis of expressed sequence tags (ESTs) and microarrays was recently undertaken in blueberry.

Two cDNA libraries were constructed using RNA from cold-acclimated (CA) and nonacclimated (NA) floral buds of 'Bluecrop'. Clones were picked at random from each of the libraries for single-pass DNA sequencing. Approximately $1200 \quad 5^{\prime}$-end ESTs were generated from each library (Dhanaraj et al., 2004, 2007). The highquality ESTs from each library were assembled into contigs or clusters based on the presence of overlapping, identical, or similar sequences. From contig analyses, 796 and 865 unique transcripts were identified from the CA and NA libraries, respectively. The most highly abundant cDNAs that were picked many more times from one library than from the other were identified as representing potentially differentially expressed transcripts and are shown in Tables 2 and 3.

Table 1. Maximum flower bud cold-hardiness levels and germplasm composition of field-grown blueberry plants of eight cultivars using a freeze-thaw protocol described previously ${ }^{2}$.

\begin{tabular}{lcc}
\hline Cultivar & \multicolumn{1}{c}{ Bud cold hardiness defined } \\
as temp causing $50 \%$ injury $\left(\mathrm{LT}_{50}\right)$ & Germplasm composition \\
\hline Beckyblue & -16.9 & $V$. ashei \\
Bluecrop & -25.4 & Primarily $V$. corymbosum \\
Draper & -25.5 & Primarily $V$. corymbosum \\
Duke & -25.6 & Primarily $V$. corymbosum \\
Little Giant & $\leq-28.0$ & $50 \% V$. constablaei and \\
& & $50 \%$. ashei \\
Northcountry & -28.0 & $\approx 75 \%$. corymbosum and \\
Northsky & -28.4 & $25 \%$. angustifolium \\
& & $\approx 75 \%$. corymbosum and \\
Tifblue & -20.0 & $25 \%$. angustifolium \\
Weymouth & -25.8 & $V$. ashei \\
& & $87.5 \%$. corymbosum and \\
& & $12.5 \%$. angustifolium \\
\hline
\end{tabular}

${ }^{\mathrm{z}}$ Rowland et al. (2005).

Table 2. Most abundant cDNAs from the standard CA libraryz.

\begin{tabular}{lc}
\hline Putative gene identification & No. of cDNAs $^{y}$ \\
\hline Probable cytochrome P450 monooxygenase & $23(0 \text { in NA })^{x}$ \\
Dehydrin & $14(9$ in NA) \\
F1 ATPase subunit alpha & $10(6$ in NA) \\
Early light-inducible protein & $7(1$ in NA $)$ \\
Dna J heat shock protein & $6(0$ in NA $)$ \\
Beta amylase & $6(2$ in NA $)$ \\
Mei2-like cell cycle protein & $6(0$ in NA $)$ \\
Triosephosphate isomerase, cytosolic & $6(3$ in NA $)$ \\
Putative glycerophosphodiester phosphodiesterase & $6(0$ in NA $)$ \\
Elongation factor 1-Beta (EF-1-BETA) & $6(1$ in NA $)$ \\
Putative WD-40 repeat protein & $5(1$ in NA $)$ \\
Putative 3-phosphoinositide-dependent protein kinase-1 & $5(0$ in NA $)$ \\
Enolase & $5(1$ in NA $)$ \\
Granule-bound starch synthase & $5(0$ in NA $)$ \\
Cysteine protease component of protease inhibitor complex & $5(0$ in NA $)$ \\
\hline
\end{tabular}

${ }^{\mathrm{z} T h e}$ CA library was prepared from cDNA from RNA from CA floral buds of 'Bluecrop' and $\approx 12005^{\text {' }}$-end ESTs were generated.

${ }^{y}$ Number of times a particular cDNA was picked from the CA library.

${ }^{x}$ In parentheses is the number of times a particular cDNA was picked from the NA library.

$\mathrm{CA}=$ cold acclimated; ESTs $=$ expressed sequence tags. 
Initially, before microarray analyses, we confirmed many of these genes to be coldresponsive by northern blot analyses (Dhanaraj et al., 2004). For example, of the cDNAs that were more abundant in the CA library than in the NA library, those encoding a dehydrin, probable cytochrome P450 monooxygenase, early light-inducible protein, beta amylase, and a hypothetical protein (clone CA-265) were all confirmed to be induced with low-temperature exposure. Of the cDNAs that were more abundant in the NA library than in the CA library, those encoding a histone $\mathrm{H} 3.2$ protein and BURPdomain dehydration-responsive protein $\mathrm{RD}$ 22 were confirmed to be suppressed with lowtemperature exposure (Dhanaraj et al., 2004).

A contig analysis was also performed on all the sequences together from both libraries (Dhanaraj et al., 2007). From a total of 2480 sequences (1287 from the CA library plus 1193 from the NA library), 1527 clusters were formed. These included 458 singletons from the CA library and 615 from the NA library, 204 contigs comprised of only CA ESTs, 116 contigs comprised of only NA ESTs, and 134 contigs comprised of ESTs from both libraries. Thus, only $8.8 \%$ (134 of 1527) of the total distinct transcripts were shared between the two libraries, suggesting marked differences in the genes expressed under the two conditions.

Individual ESTs and assembled contigs were compared with the National Center for Biotechnology Information (NCBI) nonredundant protein database using the BLASTX algorithm (Altschul et al., 1997). If sequences had no significant similarity with sequences in the protein database, they were then compared with the nucleotide database using BLASTN. In this way, $\approx 57 \%$ of the ESTs from both libraries were assigned putative functions based on sequence similarity to genes or proteins of known function in GenBank. Of the remaining sequences, $27 \%$ showed significant similarity to protein or DNA sequences that were of unknown function and $16 \%$ had no significant similarity to any other sequences in the databases (Dhanaraj et al., 2004).

\section{TRANSCRIPT PROFILES OF BLUEBERRY DURING COLD ACCLIMATION UNDER FIELD AND COLD ROOM CONDITIONS USING CDNA MICROARRAYS}

The clone inserts from the CA and NA libraries, from which the ESTs were generated, were then used to construct cDNA microarrays. The microarrays were used to examine changes in abundance of gene transcripts in floral buds of blueberry at multiple times during cold acclimation under field and cold room conditions (Dhanaraj et al., 2007). Both field and cold room conditions were studied because there are advantages (and disadvantages) of both systems. First, the purpose of this research was to identify genes potentially involved not just in cold stress, but in cold acclimation. In woody perennials, cold acclimation is triggered by several environmental cues, short photoperiod, low temperature, available moisture, and so on. Second, for construction of the CA library, we wanted maximally winter-hardy plants. Cold-treated greenhouse plants cannot achieve the maximum level of cold hardiness reached by field plants. Field plants have the advantage in this type of study over coldtreated greenhouse plants of acclimating to cold under natural conditions, to progressively shorter photoperiods, and colder temperatures. Floral buds of 'Bluecrop', in particular, reach a maximum cold-hardiness level [temperature causing $50 \%$ injury $\left(\mathrm{LT}_{50}\right)$ ] that is 2 to $3{ }^{\circ} \mathrm{C}$ lower under field conditions than in the cold room (Arora et al., 1997; Muthalif and Rowland, 1994; Rowland et al., 2005). Figure 1 shows the changes in cold-hardiness levels in 'Bluecrop' flower buds over time under field and cold room conditions. Under field conditions, coldhardiness levels reach a maximum $\approx 800$ chill units and then begin to decline as temperatures warm and buds begin to open. Under cold room conditions, cold-hardiness levels reach a maximum $\approx 500$ chill units and remain constant as long as plants are kept at $4{ }^{\circ} \mathrm{C}$. Third, we are not as limited with the number of plants that can be cold-acclimated and thus, the amount of flower buds that can be collected in the field as in the cold room. On the other hand, the cold room is a more controlled or "controllable" environment than the field. Other stresses may be acting in the field that would not be a factor in the cold room. Because of these considerations, we used both systems in this study and compared the results.

RNA was isolated from buds of field plants and from buds of cold room-treated greenhouse plants of 'Bluecrop' that had received various amounts of chilling $(0,70$, 400, 800, and 1200 chill units for field plants; 0,500 , and 1000 chill units for cold room plants). Fewer time points were examined in

Table 3. Most abundant cDNAs from the standard NA library ${ }^{\mathrm{z}}$.

\begin{tabular}{|c|c|}
\hline Putative gene identification & No. of cDNAs \\
\hline BURP-domain dehydration-responsive protein RD 22 & $13(1 \text { in } \mathrm{CA})^{\mathrm{x}}$ \\
\hline Dehydrin & 9 (14 in CA) \\
\hline Metallothionein-like protein & 8 ( 1 in $\mathrm{CA})$ \\
\hline Histone $\mathrm{H} 3.2 / \mathrm{H} 3.3$ protein & $6(1$ in $\mathrm{CA})$ \\
\hline F1 ATPase subunit alpha & $6(10$ in $\mathrm{CA})$ \\
\hline Major latex-like protein & $6(0$ in $\mathrm{CA})$ \\
\hline Putative glyceraldehyde-3-phosphate dehydrogenase & $5(0$ in $\mathrm{CA})$ \\
\hline Glutathione reductase, cytosolic & $5(0$ in $\mathrm{CA})$ \\
\hline
\end{tabular}

'The NA library was prepared from cDNA from RNA from NA floral buds of 'Bluecrop' and $\approx 1200$ 5' end ESTs were generated.

${ }^{y}$ Number of times a particular cDNA was picked from the NA library.

${ }^{x}$ In parentheses is the number of times a particular cDNA was picked from the CA library.

$\mathrm{NA}=$ noncold acclimated; ESTs = expressed sequence tags.

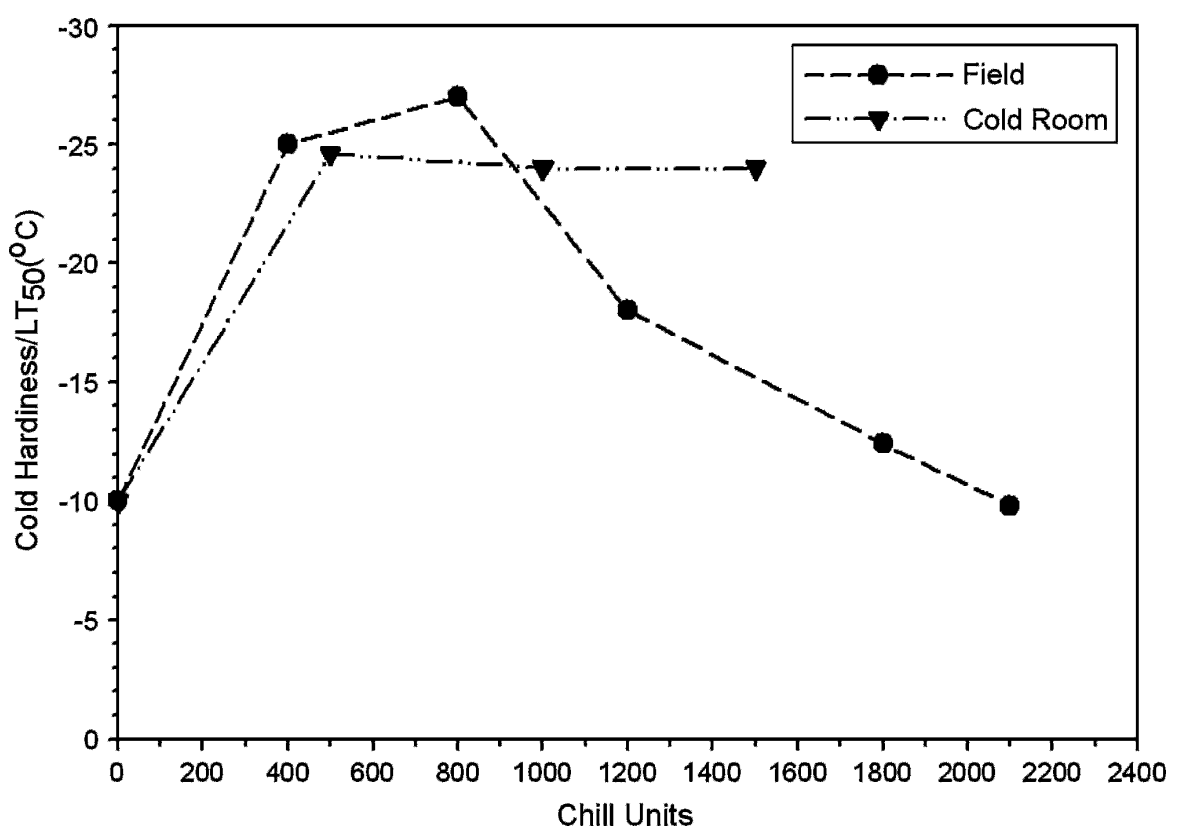

Fig. 1. Cold-hardiness levels (temperature causing 50\% injury or the $\mathrm{LT}_{50}$ from our freeze-thaw test) of 'Bluecrop' flower buds versus chilling units under field and cold room conditions. Under field conditions, cold-hardiness levels reach a maximum $\approx 800$ chill units and then begin to decline as temperatures warm and buds begin to open. Under cold room conditions, cold-hardiness levels reach a maximum $\approx 500$ chill units and remain constant as long as plants are kept in the cold room. 'Bluecrop' flower buds are generally 2 to $3{ }^{\circ} \mathrm{C}$ hardier under field conditions than under cold room conditions. 
the cold room because of the limited amount of flower bud tissue. Two biological repetitions were performed, in which RNA was extracted separately from two sets of buds from each time point. Within each biological repetition, two replicated slides were used for each time point where dye swaps were performed. Within each slide, each cDNA insert was printed in triplicate.

Microarray data were analyzed statistically using $t$ tests, analysis of variance (ANOVA), clustering algorithms, and online analytical processing. Only clones that had similar expression patterns between dye swaps and biological repetitions were used in further analyses. These were identified by single-factor ANOVA. Expression of each clone under cold-treated and untreated conditions was analyzed using $t$ tests to determine the significance of induction and suppression. If the gene induction or suppression passed the $t$ test, then a cutoff value of 1.5 -fold induction or suppression was applied for extra stringency.

Lists of all the genes induced or suppressed at any of the time points from these microarray studies are provided in supplemental tables in Dhanaraj et al. (2007). Many of the cold-induced genes identified in Arabidopsis (Fowler and Thomashow, 2002; Hannah et al., 2005; Seki et al., 2001) were identified as being highly induced in CA blueberry under both field and cold room conditions such as galactinol synthase, beta amylase, LEAs, dehydrins, and early lightinducible protein. In addition, other genes were identified as being cold-induced in blueberry under field and cold room conditions that have not been reported as cold-induced in Arabidopsis such as auxin-repressed protein, protein kinase PINOID, pectate lyaselike protein, and S-adenosylmethionine decarboxylase proenzyme. Of particular interest is PINOID, which is involved in auxinmediated signaling. In Arabidopsis, PINOID has been shown to work in concert with LEAFY to direct formation of the floral meristem (Ezhova et al., 2000; Lebedeva et al., 2005). In blueberry, it appears that PINOID is induced by low temperature. These differences between blueberry and Arabidopsis may reflect differences between woody perennials and herbaceous annuals or differences in the types of tissues analyzed. In blueberry, we are using floral buds, whereas in Arabidopsis, most of the studies have used leaf tissue or whole seedlings.

Although many of the same genes were induced and suppressed under field and cold room conditions in blueberry, there were also many differences in the types of genes expressed under the two conditions. In general, the number of cold-induced genes was lower and the number of cold-suppressed genes was higher in the field than that in the cold room. The total number of differentially induced genes during cold acclimation in the field was 134 or $5.2 \%$ of cDNAs that were arrayed. Surprisingly, the number of genes induced under cold room conditions was 241 or $9.4 \%$ of the arrayed genes, almost twice the number induced under field conditions. Many of the genes induced under cold room conditions that were not induced under field conditions could be divided into three major groups: 1) genes associated with stress tolerance; 2) those that encode glycolytic and tricarboxylic acid (TCA) cycle enzymes; and 3 ) those that encode protein synthesis machinery. Examples of some of the encoded proteins associated with stress tolerance are phospholipid hydroperoxide glutathione peroxidase, glutathione-S-transferase, metallothionein-like protein type 2, and low temperature-induced $78 \mathrm{kD}$ protein. The glycolytic and TCA cycle enzymes, whose messages were upregulated under cold room conditions but not field conditions, include phosphoglyceromutase, glyceraldehyde-3phosphate dehydrogenase, malate dehydrogenase, and succinate dehydrogenase flavoprotein alpha subunit. The protein synthesis machinery members include many $30 \mathrm{~S}, 40 \mathrm{~S}$, and $60 \mathrm{~S}$ ribosomal proteins and translation initiation factor 5A-4. The upregulation of genes involved in respiration and protein synthesis may simply relate to the observation that more genes are upregulated under cold room conditions than under field conditions, thus the need for more energy and more translation factors.

The total number of differentially suppressed genes during cold acclimation in the field was 162 or $6.3 \%$ of arrayed genes. In contrast, the number of genes suppressed in the cold room was much lower, only 32 or $1.2 \%$ of arrayed genes. It is interesting that many of the genes that were suppressed during cold acclimation in the field were, in fact, induced during cold acclimation in the cold room. Examples include genes encoding ubiquitin-conjugating enzyme, heat shock proteins, phospholipid hydroperoxide glutathione peroxidase, and low temperatureinduced $78 \mathrm{kD}$ protein. Most of the genes suppressed in the field reached maximum suppression at the $400-\mathrm{h}$ time point. An examination of the weather data revealed that, in the week before this collection point, the average temperature had dropped below freezing, to $-2.1^{\circ} \mathrm{C}$ from an average temperature of $6.3{ }^{\circ} \mathrm{C}$ the week before. Thus, we hypothesize that many of these genes may be suppressed by freezing temperatures rather than by low temperature, possibly explaining why they were not suppressed in the cold room experiment.

From this work we conclude that, although there are similarities in the types of genes that respond during cold acclimation in the cold room and in the field environment, there are major differences. There may be a general response to turn on many stress-related genes at $4{ }^{\circ} \mathrm{C}$, but once temperatures drop below freezing, many of these genes are turned off, perhaps to save energy. This also indicates that many of these stress-related genes are not, in fact, required for reaching maximum cold tolerance levels, because 'Bluecrop' field plants, which have been acclimated to winter conditions, are slightly more cold-hardy than cold room plants.
Currently, we are comparing the transcription profiles from 'Bluecrop' with those of a more cold-sensitive genotype, 'Tifblue'. Microarrays were printed and hybridized to 'Tifblue' probes at the same time as the previously described microarrays were hybridized to 'Bluecrop' probes. Although the analysis is not yet complete, preliminary results indicate that some transcripts that are highly induced by cold in 'Bluecrop' are not induced in 'Tifblue'. Also, some transcripts that are induced by cold in both 'Bluecrop' and 'Tifblue' are induced earlier and to higher levels in 'Bluecrop'. Figure 2 shows transcript profiles of some such genes. For example, transcripts of galactinol synthase and "blind", an abiotic stress protein identified in potato, were both induced more than twofold in 'Bluecrop' but were not induced in 'Tifblue' by our criteria. Transcripts of a dehydrin and a putative cell wall protein were turned on earlier, stayed on longer, and were induced to higher levels in 'Bluecrop' than in 'Tifblue' buds. In this way, by comparing transcript profiles of coldhardy and cold-sensitive genotypes, we hope to narrow down the list of cold-responsive genes to what might be the key players in the cold acclimation pathway.

\section{SUBTRACTIVE HYBRIDIZATION APPROACH TO IDENTIFY MORE COLD-RESPONSIVE GENES FROM BLUEBERRY}

Random picking and sequencing of even several thousand clones from standard cDNA libraries will result in selection of clones representing more highly abundant transcripts because these clones will be present in the libraries at a higher frequency than those representing less abundant transcripts. Important regulatory genes such as transcription factors are often expressed at rather low levels and over a shorter timeframe. Thus, they can be missed using this approach. Many transcription factors have been identified in plants that play key regulatory roles in stress responses such as AP2/EREBP, MYB/ MYC, bZIP, WRKY, and zinc finger proteins (Singh et al., 2002). Therefore, we decided to prepare forward-subtracted and reversesubtracted cDNA libraries from blueberry flower buds to supplement our microarray work, which was based on cDNAs from standard libraries and increase the chances of finding rarer classes of transcripts.

A forward-subtracted library was prepared in such a way to enrich for transcripts that are expressed at higher levels in flower buds of 'Bluecrop' field plants at $400 \mathrm{~h}$ of cold acclimation than at $0 \mathrm{~h}$ of cold acclimation and vice versa for a reverse subtracted library (Naik et al., 2007). Approximately 600 clones from the forward-subtracted library and $\approx 300$ clones from the reversesubtracted library were picked and singlepass sequenced. Contig analyses and BLAST (NCBI) searches were performed to categorize the genes. From the contig analyses, 275 unigenes (unique clones) from the 
A
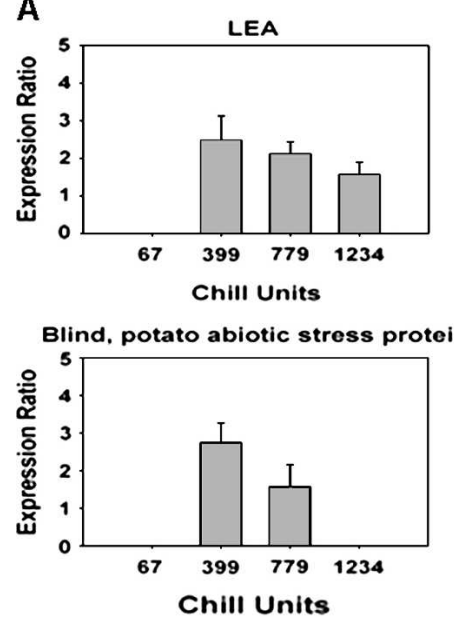
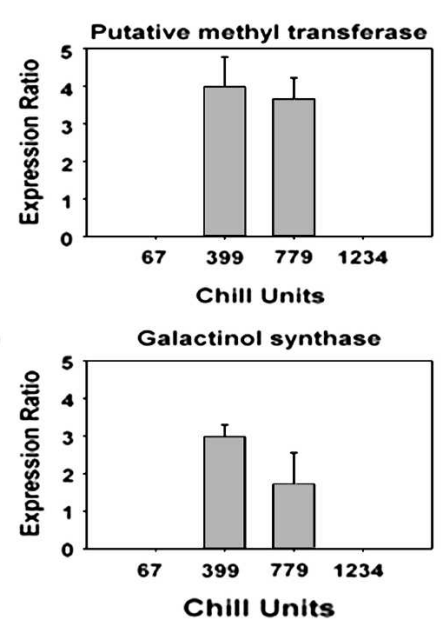

B
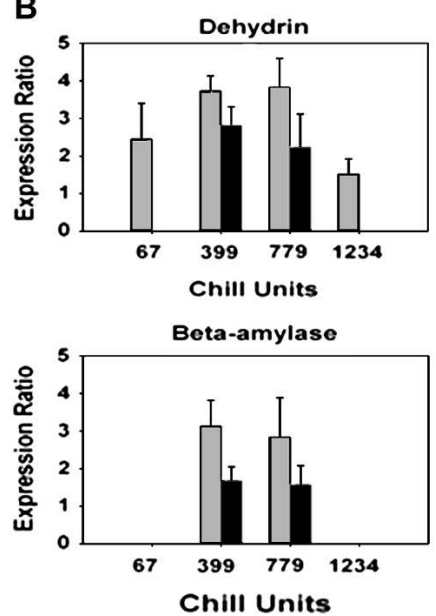

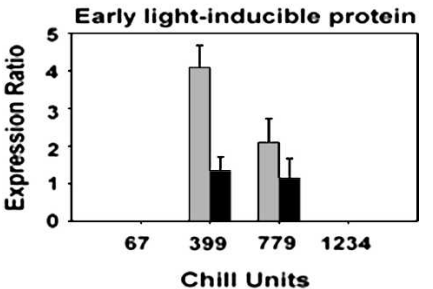

Putative cell wall protein

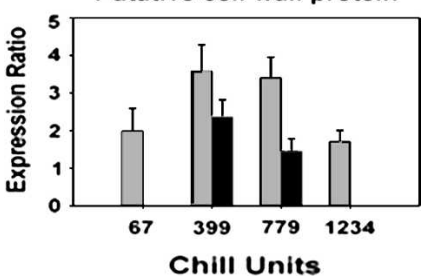

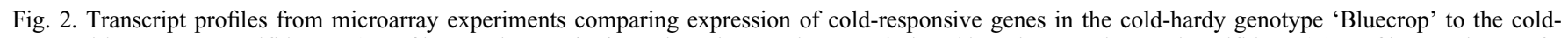
sensitive genotype 'Tifblue'. (A) Profiles are shown of a few selected genes that were induced in 'Bluecrop' but not in 'Tifblue'. (B) Profiles are shown of a few selected genes that were induced earlier, stayed on longer, and/or were induced to higher levels in 'Bluecrop' (gray bars) than in 'Tifblue' (black bars).

forward-subtracted library and 99 unigenes from the reverse-subtracted library were obtained. Using quantitative reverse transcriptase-polymerase chain reaction, expression profiles of mRNAs corresponding to 11 clones, six from the forward-subtracted library and five from the reverse-subtracted library, were examined, confirming their differential expression. Many potential regulatory genes were identified from both libraries and are now available for further testing. Some of these genes are listed in Table 4 and include calmodulin, putative myb-related protein, putative bZIP protein, zinc finger proteins, AP2 domain-containing proteins, and a basic-helix-loop-helix transcription factor, among others.

\section{AVAILABILITY OF AN ONLINE DATABASE FOR BLUEBERRY GENOMIC DATA}

Recently, we developed the first publicly available, online database for our blueberry genomics data (Alkharouf et al., 2007). The Blueberry Genomics Database (BBGD; http://psi081.ba.ars.usda.gov/BBGD/) was established to serve the blueberry and broader Ericaceae communities with its primary focus to store and analyze ESTs and microarray data generated from experiments aimed at studying cold acclimation and midwinter hardiness of blueberry (described previously). It allows for the correlation of gene function, deduced from the EST data, with expression levels, deduced from the microarray data.

The microarray and EST data are available in easy-to-search formats. Regarding the microarray data, users can choose to query a specific time point in the cold acclimation experiment, across all or selected time points, or query by gene name, ID, or GenBank accession number. Users can also conduct advanced queries to find genes that have similar expression in different experiments and/or biological samples. Results from clus-

Table 4. A selected subset of clones from each of the forward- and reverse-subtracted libraries and their GenBank accession numbers ${ }^{2}$.

\begin{tabular}{llc}
\hline Putative gene identification & Clone name & Accession number \\
\hline Forward-subtracted library & & \\
ABA-induced membrane protein & SL282 & DW043270 \\
Ca2+/H+ exchanging protein & SL9 & DW043562 \\
Calmodulin-binding family protein & SL236 & DW043225 \\
Calmodulin-related protein & SL69 & DW043542 \\
Class III HD-Zip protein 2 & SL426 & DW043423 \\
DNA-binding protein & SL384 & DW043380 \\
Dormancy-associated protein & SL290 & DW043279 \\
Protein kinase family protein & SL65 & DW043538 \\
Protein phosphatase PP1 & SL400 & DW043398 \\
Putative myb-related protein & SL417 & DW043413 \\
Putative ripening-related bZIP protein & SL190 & DW043182 \\
Zinc finger proteins & SL4 & DW043396 \\
& SL26 & DW043246 \\
Reverse-subtracted library & SL353 & DW043348 \\
AP2 domain-containing proteins & & \\
& RL24 & DW043040 \\
Basic helix-loop-helix transcription factor & RL101 & DW042990 \\
Calmodulin & RL49 & DW043058 \\
Mitogen-activated protein kinase 1 & RL143 & DW043018 \\
PERK1-like protein kinase & RL10 & DW042988 \\
Putative calcium-binding protein & RL9 & DW043080 \\
Putative DNA-binding protein & RL35 & DW043047 \\
RING zinc-finger protein & RL22 & DW043037 \\
Transcriptional activator RF2a & RL51 & DW043061 \\
\hline
\end{tabular}

${ }^{2}$ The forward-subtracted library was enriched for transcripts expressed at higher levels in floral buds of 'Bluecrop' plants at $400 \mathrm{~h}$ of cold acclimation than at $0 \mathrm{~h}$ of cold acclimation and vice versa for the reversesubtracted library.

ter analysis and online analytical processing are also displayed. Regarding the EST data, results of EST analysis and contig assembly for the EST libraries, along with graphical representations and charts, are available. Like the microarray portion, users can query the sequence database by gene name, ID, or GenBank accession number. Users can also browse a specific library in a table format (see Fig. 3).

An example of how we are currently using the EST database is in the ongoing development of EST-polymerase chain reaction markers for mapping, DNA fingerprinting, and genetic relationship studies of blueberry (Rowland et al., 2003). By designing poly- merase chain reaction primer pairs from the ends of available EST sequences to amplify as much of each gene as possible, we can detect length polymorphisms at a high enough frequency to be useful for mapping in our diploid $V$. darrowi Camp $\times V$. corymbosum-derived mapping populations that are segregating for cold hardiness. Because we are trying to identify QTL for cold hardiness in these populations, we are currently attempting to map as many of the coldresponsive genes identified from our microarray study as we can, because they are good candidate genes for controlling cold hardiness. We can also detect polymorphisms at a 


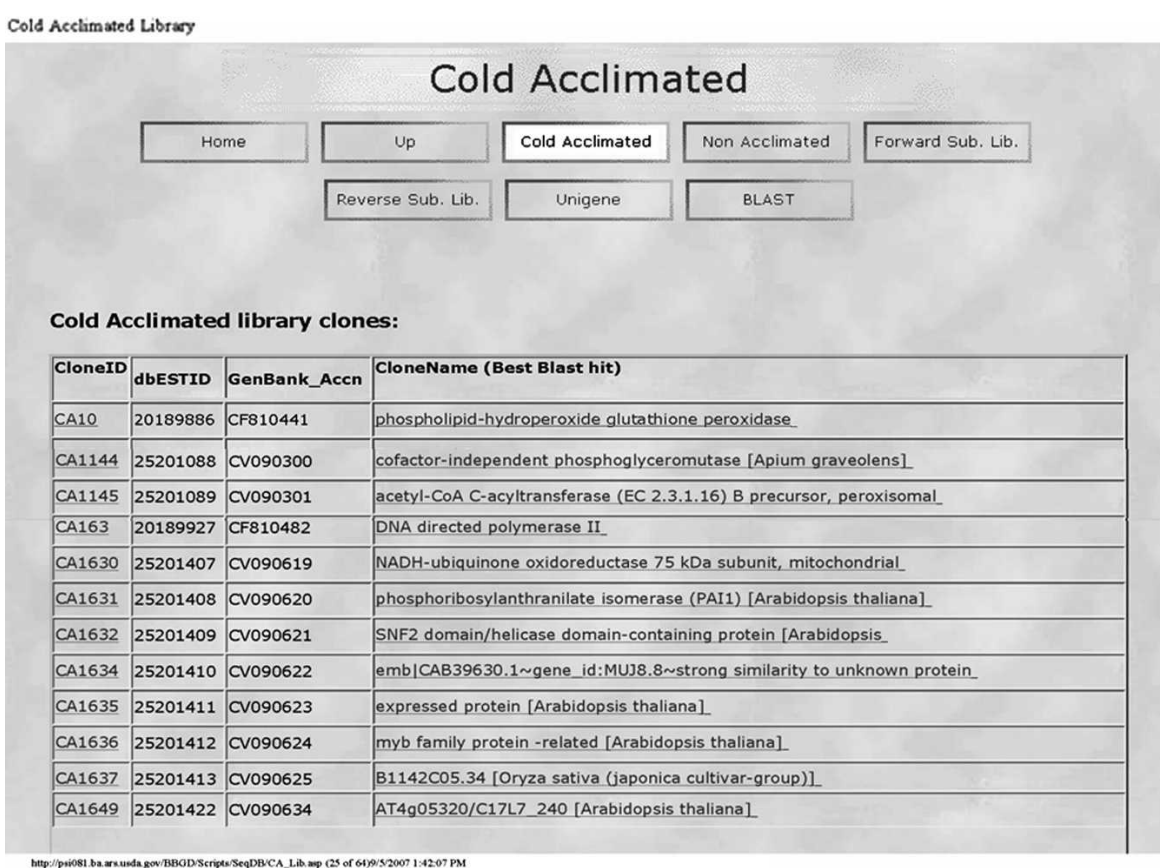

Fig. 3. The sequence database from the BBGD web site (http://psi081.ba.ars.usda.gov/BBGD/) allows users to browse a specific library in table format. This snapshot represents part of the table that was returned by the database. Users can get the sequence by clicking on the clone ID and/or can query PubMed for relevant articles by clicking on the gene name.

high enough frequency within species of $V$. corymbosum and $V$. ashei to be useful for DNA fingerprinting and genetic relationship studies as well.

\section{CONCLUSIONS}

In summary, since identifying and cloning genes that encode dehydrins, some of the most abundant proteins in flower buds of blueberry during the winter, we have begun taking a genomic approach to identify other cold-responsive genes. We have obtained 5' end sequences from $\approx 2400$ to 2500 cDNA clones from standard cDNA libraries from flower buds of CA and NA 'Bluecrop' plants. We have prepared forward- and reversesubtracted libraries enriched for less abundant cold-responsive genes, as well, and sequenced $\approx 600$ and 300 clones from each, respectively. We have performed contig analyses on the ESTs and identified the most abundant cDNAs from each of the libraries. We have performed microarray experiments to identify cold-responsive genes in 'Bluecrop' under field and cold room conditions. From the microarray work, we found many more genes induced under cold room conditions than field conditions, including genes associated with: 1) stress tolerance; 2) glycolytic and TCA cycle enzymes; and 3) protein synthesis machinery. There are many possible explanations for the differences in the two responses. Of course, the field and cold room conditions are very different. In the cold room, plants are exposed to a constant temperature of $4{ }^{\circ} \mathrm{C}$ and constant 10 -h photoperiod. In the field, plants are exposed to fluctuating and freezing temperatures, gradually decreasing then gradually increasing daylength, different intensity of light and spectrum of light, and so on. We hypothesize that exposure to freezing temperatures versus $4{ }^{\circ} \mathrm{C}$ probably explains many of the observed differences. We are currently analyzing microarray data from a cold-sensitive cultivar, Tifblue, and comparing the results with those from 'Bluecrop'. From the forward- and reverse-subtracted libraries, we identified many interesting coldresponsive genes, too, including several possible transcription factors. To store and make publicly available the blueberry genomic data, we have set up the Blueberry Genomic Database, which is accessible on the Internet. We are currently using the EST database for developing EST-polymerase chain reaction markers, which are proving useful for mapping and genetic diversity studies.

\section{Literature Cited}

Alkharouf, N.W., A.L. Dhanaraj, D. Naik, C. Overall, B.F. Matthews, and L.J. Rowland. 2007. BBGD: An online database for blueberry genomic data. Biomed Central Plant Biology 7:5.

Altschul, S.F., T.L. Madden, A.A. Schaffer, J. Zhang, A. Zhang, W. Miller, and D.J. Lipmann. 1997. Gapped BLAST and PSI-BLAST: A new generation of protein database search programs. Nucleic Acids Res. 25:3389-3402.

Arora, R., L.J. Rowland, J.S. Lehman, C.C. Lim, G.R. Panta, and N. Vorsa. 2000. Genetic analysis of freezing tolerance in blueberry (Vaccinium section Cyanococcus). Theor. Appl. Genet. 100:690-696.

Arora, R., L.J. Rowland, and G.R. Panta. 1997. Chill responsive dehydrins in blueberry: Are they associated with cold hardiness or dormancy transitions? Physiol. Plant. 101:8-16.

Byrne, M., J.C. Murrell, J.V. Owen, E.R. Williams, and G.F. Moran. 1997. Mapping of quantitative trait loci influencing frost tolerance in Eucalyptus nitens. Theor. Appl. Genet. 95:975-979. Close, T.J. 1996. Dehydrins: Emergence of a biochemical role of a family of plant dessication proteins. Physiol. Plant. 97:795-803.

Dhanaraj, A.L., N.W. Alkharouf, H.S. Beard, I.B. Chouikha, B.F. Matthews, H. Wei, R. Arora, and L.J. Rowland. 2007. Major differences observed in transcript profiles of blueberry during cold acclimation under field and cold room conditions. Planta 225:735-751.

Dhanaraj, A.L., J.P. Slovin, and L.J. Rowland. 2004. Analysis of gene expression associated with cold acclimation in blueberry floral buds using expressed sequence tags. Plant Sci. 166: 863-872.

Dhanaraj, A.L., J.P. Slovin, and L.J. Rowland. 2005. Isolation of a cDNA clone and characterization of expression of the highly abundant, cold acclimation-associated $14 \mathrm{kDa}$ dehydrin of blueberry. Plant Sci. 168:949-957.

Ezhova, T.A., O.P. Soldatova, A.I. Kalinina, and S.S. Medvedev. 2000. Interaction of ABRUPTUS/PINOID and LEAFY genes during floral morphogenesis in Arabidopsis thaliana (L.) Heynh. Genetika 36:1682-1687.

Fowler, S. and M.F. Thomashow. 2002. Arabidopsis transcriptome profiling indicates that multiple regulatory pathways are activated during cold acclimation in addition to the CBF cold response pathway. Plant Cell 14:1675-1690.

Guilmour, S.J., A.M. Sebolt, M.P. Salazar, J.D. Everard, and M.F. Thomashow. 2000. Overexpression of the Arabidopsis CBF3 transcriptional activator mimics multiple biochemical changes associated with cold acclimation. Plant Physiol. 124:1854-1865.

Guy, C. 1999. Molecular responses of plants to cold shock and cold acclimation. J. Mol. Microbiol. Biotechnol. 1:231-242.

Guy, C.L. 1990. Cold acclimation and freezing stress tolerance: Role of protein metabolism. Ann. Rev. Plant Physiol. Plant Mol. Biol. 41: 187-223.

Hannah, M.A., A.G. Heyer, and D.K. Hincha. 2005. A global survey of gene regulation during cold acclimation in Arabidopsis thaliana. PLoS Genetics 1:179-196.

Howe, G.T., P. Saruul, J. Davis, and T.H.H. Chen. 2000. Quantitative genetics of bud phenology, frost damage, and winter survival in an $F_{2}$ family of hybrid poplars. Theor. Appl. Genet. 101:632-642.

Jaglo-Ottosen, K.R., S.J. Guilmour, D.G. Zarka, O. Schabenberger, and M.F. Thomashow. 1998. Arabidopsis CBF1 overexpression induces COR genes and enhances freezing tolerance. Science 280:104-106.

Jermstad, K.D., D.L. Bassoni, N.C. Wheeler, T.S. Anekonda, S.N. Aitken, W.T. Adams, and D.B. Neale. 2001. Mapping of quantitative trait loci controlling adaptive traits in coastal Douglasfir. II. Spring and fall cold-hardiness. Theor. Appl. Genet. 102:1152-1158

Kacperska-Palacz, A. 1978. Mechanism of cold acclimation in herbaceous plants, p. 139-152. In: Li, P.H and A. Sakai (eds.). Plant cold hardiness and freezing stress: Mechanism and crop implications. Academic, New York, NY.

Kasuga, M., O. Liu, M. Setsuko, K. YamaguchiShinozaki, and K. Shinozaki. 1999. Improving plant drought, salt, and freezing tolerance by gene transfer of a single stress-inducible transcription factor. Nat. Biotechnol. 17:287291.

Kaye, C., L. Neven, A. Hofig, Q.B. Li, D. Haskell, and C. Guy. 1998. Characterization of a gene 
for spinach CAP160 and expression of two spinach cold-acclimated proteins in tobacco. Plant Physiol. 116:1367-1377.

Lebedeva, O.V., U.N. Ondar, A.A. Penin, and T.A. Ezhova. 2005. Effect of the ABRUPTUS/ PINOID gene on expression of the LEAFY gene in Arabidopsis thaliana. Genetika 41: 559-565.

Levi, A., G.R. Panta, C.M. Parmentier, M.M. Muthalif, R. Arora, S. Shanker, and L.J. Rowland. 1999. Complementary DNA cloning, sequencing, and expression of an unusual dehydrin from blueberry floral buds. Physiol. Plant. 107:98-109.

Maruyama, K., Y. Sakuma, M. Kasuga, Y. Ito, M. Seki, H. Goda, Y. Shimada, S. Yoshida, K. Shinozaki, and K. Yamaguchi-Shinozaki. 2004. Identification of cold-inducible downstream genes of the Arabidopsis DREB1A/ CBF3 transcription factor using two microarray systems. Plant J. 38:982-993.

Moore, J.N. 1993. The blueberry industry of North America. Acta Hort. 346:15-26.

Muthalif, M.M. and L.J. Rowland. 1994. Identification of dehydrin-like proteins responsive to chilling in floral buds of blueberry (Vaccinium, section Cyanococcus). Plant Physiol. 104:1439-1447.

Naik, D., A.L. Dhanaraj, R. Arora, and L.J. Rowland. 2007. Identification of genes associated with cold acclimation in blueberry (Vaccinium cor- ymbosum L.) using a subtractive hybridization approach. Plant Sci. 173:213-222.

Owens, C.L., M.F. Thomashow, J.F. Hancock, and A.F. Iezzoni. 2002. CBF1 orthologs in sour cherry and strawberry and the heterologous expression of $C B F 1$ in strawberry. J. Amer. Soc. Hort. Sci. 127:489-494.

Parker, J. 1963. Cold resistance in woody plants. Bot. Rev. 29:124-201.

Powell, L.E. 1987. Hormonal aspects of bud and seed dormancy in temperate-zone woody plants. HortScience 22:845-850.

Quamme, H.A. 1985. Winter hardiness research in North America on woody perennials. Acta Hort. 168:191-194.

Rowland, L.J., S. Mehra, A.L. Dhanaraj, E.L. Ogden, J.P. Slovin, and M.K. Ehlenfeldt 2003. Development of EST-PCR markers for DNA fingerprinting and genetic relationship studies in blueberry (Vaccinium, section Cyanococcus). J. Amer. Soc. Hort. Sci. 128:682690.

Rowland, L.J., E.L. Ogden, M.K. Ehlenfeldt, and B. Vinyard. 2005. Cold hardiness, deacclimation kinetics, and bud development among 12 diverse blueberry genotypes under field conditions. J. Amer. Soc. Hort. Sci. 130:508-514.

Sakai, A. and W. Larcher. 1987. Frost survival of plants: Responses and adaptation to freezing stress. Springer, Berlin, Heidelberg, New York. Seki, M., M. Narusaka, H. Abe, M. Kasuga, K. Yamaguchi-Shinozaki, P. Carninci, Y.
Hayashizaki, and K. Shinozaki. 2001. Monitoring the expression pattern of 1300 Arabidopsis genes under drought and cold stresses by using a full-length cDNA microarray. Plant Cell 13:61-72.

Shinozaki, K. and K. Yamaguchi-Shinozaki. 1996. Molecular responses to drought and cold stress. Curr. Opin. Biotechnol. 7:161-167.

Shinozaki, K. and K. Yamaguchi-Shinozaki. 2000. Molecular responses to dehydration and low temperature: Differences and cross-talk between two stress signaling pathways. Curr. Opin. Biotechnol. 3:217-223.

Singh, K., R.C. Foley, and L. Onate-Sanchez. 2002. Transcription factors in plant defense and stress responses. Curr. Opin. Plant Biol. 5:430-436.

Sutinen, M.L., J.P. Palta, and P.B. Reich. 1992. Seasonal differences in freezing stress resistance of needles of Pinus nigra and Pinus resinosa: Evaluation of the electrolyte leakage method. Tree Physiol. 11:241-254.

Thomashow, M. 2001. So what's new in the field of plant cold acclimation? Lots! Plant Physiol. 125:89-93.

Thomashow, M.F. 1999. Plant cold acclimation: Freezing tolerance genes and regulatory mechanisms. Ann. Rev. Plant. Physiol. Plant. Mol. Biol. 50:573-599.

Weiser, C.J. 1970. Cold resistance and injury in woody plants. Science 169:1269-1278. 